\title{
Épocas de semeadura e desempenho qualitativo de sementes de soja ${ }^{1}$
}

\author{
Elesandro Bornhofen ${ }^{2}$, Giovani Benin², Danielle Galvan², Mariana Faber Flores ${ }^{2}$
}

\begin{abstract}
Sowing seasons and qualitative

performance of soybean seeds

Changes in the soybean sowing season directly reflect on the physiological potential of the seeds produced. This study aimed to identify sowing seasons that qualitatively improve the soybean seeds yield. The experiments were conducted in two growing seasons, in a $2 \times 4 \times 6$ factorial scheme, with four sowing seasons and six soybean cultivars (Don Mario 5.8i RR, BMX Energia RR, BMX Força RR, BRS 255 RR, BRS 294 RR and BRS 295 RR). A complete randomized blocks design, with three replications, was used. Twelve informative quality characteristics of soybean seeds were evaluated, based on tests of germination, mechanical damage, accelerated aging and tetrazolium. The sowing season and cultivars significantly affected seed quality. A difference in the sensitivity of cultivars to variations in the sowing season was noticed, concerning seed quality attributes. Sowings in mid-December are recommended for high quality seed production.
\end{abstract}

KEY-WORDS: Glycine $\max (\mathrm{L}$.$) ; germination; tetrazolium.$

\section{INTRODUÇÃO}

A soja [Glycine $\max (\mathrm{L}$.$) Merr.] é a mais$ importante leguminosa cultivada atualmente no mundo. No Brasil, é a commodity de maior importância no cenário agrícola, principalmente em virtude do volume produzido (aproximadamente 82,0 milhões de toneladas) e exportado (aproximadamente 41,9 milhões de toneladas) (USDA 2014), contribuindo significativamente para o superávit da balança comercial. Para atender essa produção, a demanda por sementes ultrapassa 1 milhão de toneladas (FAO 2014). Nesse sentido, é crucial a produção de sementes com qualidade satisfatória para o estabelecimento adequado da cultura e obtenção de rendimentos satisfatórios.

\section{RESUMO}

Variações na época de semeadura da soja refletem diretamente no potencial fisiológico das sementes produzidas. Este estudo objetivou identificar épocas de semeadura que maximizem qualitativamente a produção de sementes de soja. Os experimentos foram desenvolvidos em dois anos agrícolas, em esquema fatorial $2 \times 4 \times 6$, com quatro épocas de semeadura e seis cultivares de soja (Don Mario 5.8i RR, BMX Energia RR, BMX Força RR, BRS 255 RR, BRS 294 RR e BRS 295 RR). Utilizou-se o delineamento de blocos casualizados, com três repetições. Foram avaliadas doze características informativas da qualidade de sementes de soja, por meio dos testes de germinação, dano mecânico, envelhecimento acelerado e tetrazólio. Houve efeito significativo da época de semeadura e de cultivares sobre a qualidade das sementes. Constatou-se diferença na sensibilidade das cultivares a variações na época de semeadura, quanto aos atributos qualitativos de semente. Semeaduras em meados de dezembro são recomendadas para a produção de sementes com qualidade superior.

PALAVRAS-CHAVE: Glycine $\max (\mathrm{L}$.); germinação; tetrazólio.

A soja está distribuída em todas as regiões brasileiras e, portanto, a produção de sementes ocorre em diversas condições de ambientes. $\mathrm{O}$ seu desenvolvimento é afetado por vários fatores ambientais, tais como temperatura, precipitação, umidade (solo e ar) e fotoperíodo (Ávila et al. 2003). A época de semeadura tem maior efeito na produção de sementes do que qualquer outra técnica cultural (Motta et al. 2002, Albrecht et al. 2008, Kandil et al. 2012). Em termos econômicos, a época de semeadura é a prática de manejo que pode alterar de maneira mais significativa a quantidade e qualidade do rendimento final, com reduzido dispêndio de recursos.

Épocas de semeadura podem afetar a produtividade (Amorim et al. 2011, Kandil et al. 2012), a composição (Jaureguy et al. 2013) e a qualidade 
fisiológica de sementes de soja (Pereira et al. 2000, Motta et al. 2002, Ávila et al. 2003, Rahman et al. 2013). A qualidade é a meta prioritária no processo de produção de sementes de qualquer cultura, uma vez que dela dependem a germinação e a emergência das plântulas (Vasconcelos et al. 2009).

Inúmeros trabalhos investigando o efeito da época de semeadura na qualidade de sementes de soja são descritos na literatura nacional (Pereira et al. 2000, Ávila et al. 2003, Stülp et al. 2009), porém, com ampla variabilidade de resultados. Nesse contexto, é primordial que estudos sobre época de semeadura sejam realizados para cada condição específica de ambiente, ou seja, regionalizadamente, devido à variabilidade de condições ambientais (Amorim et al. 2011, Meotti et al. 2012).

Dependendo do sistema de sucessão/rotação, a época de semeadura pode ser alocada inclusive fora do zoneamento agroclimático. Como exemplo, tem-se a soja semeada antecipadamente, visando ao cultivo de milho safrinha (Albrecht et al. 2008, Stülp et al. 2009). Também, em algumas regiões do Estado do Paraná, verifica-se a presença de soja safrinha, semeada em meados de janeiro, a qual totalizou mais de 63 mil hectares, na safra 2011/2012 (Paraná 2014). Mesmo dentro do zoneamento há grande variação de condições fotoperiódicas, de radiação solar e de temperatura, as quais exercem demasiada influência sobre os componentes de rendimento e atributos qualitativos de sementes de soja. Além disso, semeaduras tardias reduzem o ciclo (Meotti et al. 2012), alteram a captação de radiação (Schöffel \& Volpe 2001) e o particionamento de fotoassimilados (Pedersen \& Lauer 2004).

Objetivou-se, com o presente estudo, verificar o impacto causado por diferentes épocas de semeadura em atributos qualitativos de sementes de soja e identificar, com precisão, a melhor época de semeadura para a produção de sementes, com foco na região oeste do Estado de Santa Catarina.

\section{MATERIAL E MÉTODOS}

O experimento de campo foi instalado em sistema plantio direto, nas safras agrícolas 2008/2009 e 2009/2010, no município de São Domingos, no oeste do Estado de Santa Catarina (263' S, 52 $31^{\circ}$ 'W e altitude de $635 \mathrm{~m}$ ), que apresenta clima subtropical úmido, classificado como Cfa, segundo Köppen (Ometto 1981). O cenário climático registrado du- rante o desenvolvimento da cultura, nos dois anos de experimentação, pode ser observado na Figura 1.

O delineamento experimental foi o de blocos casualizados, com três repetições. Os tratamentos seguiram um esquema fatorial $2 \times 6 \times 4$ (safra agrícola, cultivares de soja e épocas de semeadura).

Foram selecionadas três cultivares com hábito de crescimento indeterminado (Don Mario 5.8i - GM (grupo de maturação) $=5,5$; BMX Energia RR - GM = 5,6; e BMX Força RR - GM =6,2) e três de hábito de crescimento determinado (BRS $255 \mathrm{RR}-\mathrm{GM}=6,7$; BRS 294 RR - $\mathrm{GM}=6,3$; e BRS $295 \mathrm{RR}$ - $\mathrm{GM}=6,5$ ).

As épocas de semeadura consistiram nas datas 15/10 (E1), 15/11 (E2), 15/12 (E3) e 15/01 (E4), para cada safra agrícola. Destas épocas, apenas a $\mathrm{E} 4$ não está englobada no zoneamento agroclimático de risco para a cultura da soja, no Estado de Santa Catarina (Thomé et al. 1997).

Cada unidade experimental consistiu de 4 linhas de 4,0 m de comprimento, espaçadas em 0,45 m entre si, totalizando uma área de $7,2 \mathrm{~m}^{2}$. Foram considerados como área útil da parcela os $4,0 \mathrm{~m}$ centrais das duas fileiras internas, totalizando $3,6 \mathrm{~m}^{2}$.

A semeadura foi realizada de forma manual, em solo manejado no sistema plantio direto, utilizando-se densidades que oscilaram entre $12 \mathrm{e}$ 18 sementes por metro linear, de acordo com as recomendações para cada cultivar. Nos dois anos de estudo, a cultura antecessora à instalação do experimento foi o trigo.

Anteriormente à semeadura, foi efetuada a dessecação das plantas daninhas existentes na área, com o herbicida glifosato ( $960 \mathrm{~g}$ i. a. ha $\left.{ }^{-1}\right)$. A adubação e os demais tratos culturais, incluindo o controle de plantas daninhas, pragas e doenças, seguiram as recomendações técnicas para a cultura da soja (Merotto Junior \& Vidal 2008).

A marcação das linhas e distribuição do adubo foi realizada utilizando-se semeadora-adubadora tratorizada e a colheita efetuada manualmente, quando as plantas estavam no estádio R8 (Costa \& Marchezan 1982), sendo trilhadas por máquina estacionária.

A massa de sementes proveniente de cada parcela foi limpa em máquina de fluxo de ar, embalada em saco de papel kraft e armazenada em câmara fria, sob temperatura de $15^{\circ} \mathrm{C}$ e umidade relativa de $50 \%$.

Nos testes laboratoriais, cada unidade experimental constituiu-se de um lote de sementes e a amostra de trabalho foi composta por $0,5 \mathrm{~kg}$ de sementes. Posteriormente, os efeitos de diferentes épocas de 

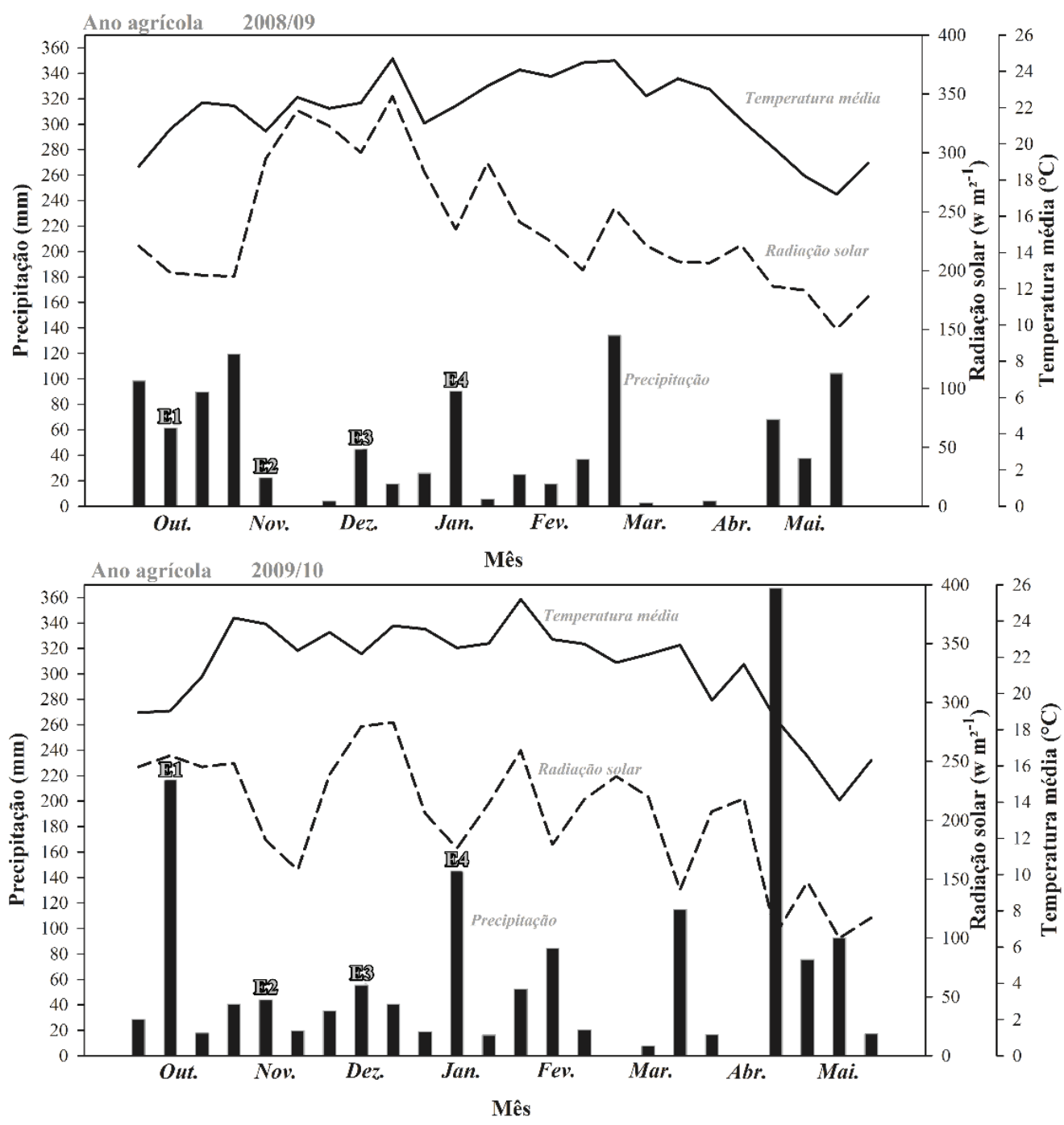

Figura 1. Cenário climático para as safras 2008/2009 e 2009/2010, incluindo precipitação (acumulada a cada 10 dias), radiação e temperatura (valores médios de 10 dias). Épocas de semeadura: $\mathrm{E} 1=15 / 10, \mathrm{E} 2=15 / 11, \mathrm{E} 3=15 / 12$ e E4 = 15/01. Fonte: Simepar (2010), estação meteorológica de Pato Branco (PR).

semeadura na qualidade fisiológica das sementes foram avaliados por meio dos seguintes testes:

Germinação: utilizaram-se quatro repetições de 100 sementes, distribuídas em rolos de papel Germitest $^{\circledR}$ umedecidos com quantidade de água equivalente a 2,5 vezes a massa do substrato seco e acondicionados em germinador do tipo Mangelsdorf, regulado a $25^{\circ} \mathrm{C}$. A porcentagem de plântulas normais foi calculada aos oito dias após o início do teste (Brasil 2009);

Envelhecimento acelerado: foram utilizadas caixas plásticas (Gerbox $250 \mathrm{ml}$ ) com $40 \mathrm{ml}$ de água destilada. As sementes foram dispostas sobre tela, no interior dessas caixas, em camada única, sem contato com a água. As sementes, com umidade inicial apro- ximada de $13 \%$, permaneceram por 48 horas a $41^{\circ} \mathrm{C}$, em BOD (Marcos Filho 1999). Após esse período, as sementes foram envolvidas em papel Germitest ${ }^{\mathbb{R}} \mathrm{e}$ postas para germinar, de acordo com o procedimento de germinação descrito anteriormente. Na sequência, foi determinada a porcentagem de plântulas normais;

Teste de tetrazólio: foram utilizadas 100 sementes (duas repetições de 50 sementes), pré-condicionadas em papel de germinação umedecido (2,5 vezes a sua massa, em água), durante 16 horas, à temperatura de $25{ }^{\circ} \mathrm{C}$, em BOD. Posteriormente, as sementes de cada tratamento foram colocadas em um becker e imersas em solução com concentração de $0,075 \%$ de 2,3,5-trifenil-cloreto-de-tetrazólio. Em seguida, os recipientes foram mantidos no es- 
curo, à temperatura de $35^{\circ} \mathrm{C}$, por 3 horas, para o desenvolvimento da coloração. Após a drenagem da solução e lavagem das sementes, foram avaliados os danos mecânicos e os danos causados por percevejo e por umidade, classificando-se, assim, as sementes quanto ao vigor e viabilidade, em níveis de 1-8 e 6-8 (sementes inviáveis) (França Neto et al. 1998);

Massa de mil sementes: mensurada a partir de uma amostragem de sementes de cada unidade experimental. $\mathrm{O}$ valor do caractere foi obtido por meio da determinação da massa de 100 sementes, em quadruplicata, e, posteriormente, estimado para 1.000 sementes. Os resultados foram expressos em gramas, com correção de umidade para $13 \%$ (base úmida) (Brasil 2009);

Dano mecânico: a ruptura do tegumento das sementes, devido a danos no processo de trilha, foi avaliada a partir de 4 repetições de 50 sementes por unidade experimental (Krzyzanowski et al. 2004). As sementes foram imersas por 10 minutos em água destilada contendo hipoclorito de sódio (5\%) e, em seguida, espalhadas sobre folhas de papel toalha, para a determinação da porcentagem de sementes danificadas.

Os dados foram submetidos ao teste de normalidade (teste de Lilliefors) e, na sequência, sofreram transformação do tipo raiz quadrada $[\sqrt{ }(x+1 / 2)$, em que x é o valor de cada observação]. Objetivou-se, com a transformação, atender às pressuposições básicas do modelo matemático da análise de variância. A análise de variância foi efetuada de forma conjunta, visto que a razão entre o maior e o menor quadrado médio do erro não foi superior a sete $(>\mathrm{QMR} /<$ QMR $\leq 7)$. Os efeitos de ano e época de semeadura foram considerados como aleatórios e o efeito de cultivar como fixo. Depois de detectadas diferenças significativas pelo teste $\mathrm{F}(\mathrm{p} \leq 0,05)$, foram efetuadas comparações de médias pelo teste Tukey $(\mathrm{p} \leq 0,05)$, para os fatores época de semeadura e cultivar de soja. As análises foram realizadas com o auxílio do programa estatístico Genes (Cruz 2013).

A metodologia GGE biplot (Yan 2001), embasada nos conceitos biplot (Gabriel 1971) e GGE (Yan et al. 2000), foi utilizada para gerar inferências visuais a respeito das associações entre as variáveis analisadas e os fatores testados. Adicionalmente, foi utilizado o método estatístico Addictive Main Effects and Multiplicative Interaction - AMMI (Zobel et al. 1988), em que, a partir da análise de variância do modelo, foram estimadas as porcentagens de explicação dos efeitos principais de genótipo (G), ambiente (A) e interações genótipos x ambientes (IGA), na variação fenotípica total. O método AMMI permite uma análise mais detalhada da IGA, além de proporcionar estimativas mais precisas das respostas genotípicas (Zobel et al. 1988).

\section{RESULTADOS E DISCUSSÃO}

Não foi observado impedimento de ordem climática ao longo do desenvolvimento da cultura, com exceção do período compreendido entre março e abril de 2009, quando se registrou menor precipitação pluviométrica (Figura 1). No decorrer da condução do experimento, as médias de temperatura observadas mantiveram-se abaixo de $22^{\circ} \mathrm{C}$, em $2008 / 2009$, e de $18{ }^{\circ} \mathrm{C}$, em 2009/2010. A qualidade de sementes de soja é maximizada quando o cultivo é realizado sob temperaturas inferiores a $22{ }^{\circ} \mathrm{C}$ (Costa et al. 1994, Marcos Filho 2005). O fato de o município estar próximo a $700 \mathrm{~m}$ de altitude favorece a ocorrência de temperaturas amenas.

Em determinadas condições de época de semeadura e cultivar de soja, ocorreram precipitações na pré-colheita. De acordo com Costa et al. (1994), melhor qualidade de sementes é obtida quando o período de maturação fisiológica até a colheita ocorre em clima seco.

Resultados da análise de variância conjunta revelaram efeito significativo $(\mathrm{p} \leq 0,05)$ das épocas de semeadura e cultivares de soja sobre os doze caracteres avaliados. Isso indica que há resposta diferencial do conjunto de cultivares, quando submetidas a diferentes épocas de semeadura. Nesse sentido, o estudo para a identificação de épocas que proporcionem melhor qualidade fisiológica de sementes é justificado. Os coeficientes de variação encontrados foram de baixa magnitude (Tabela 1), com exceção do teste de tetrazólio (Tabela 2). Considerando-se as características do teste de tetrazólio, é comum que ocorram coeficientes de variação de magnitude mais elevada (Pereira et al. 2000, Toledo et al. 2012).

Os caracteres germinação e vigor de sementes de soja são influenciados pela cultivar e época de semeadura (Rahman et al. 2013). Na época de semeadura E3 (15/12), foram observados os melhores valores de envelhecimento acelerado, germinação, vigor e viabilidade (Tabela 1), indicativos da maior qualidade fisiológica das sementes de soja.

Estudos realizados no Estado do Paraná identificaram as épocas de semeadura de 03/11 a 20/11, 
Tabela 1. Performance média das épocas de semeadura e cultivares de soja, para seis caracteres determinantes da qualidade fisiológica de sementes (São Domingos, SC, safras 2008/2009 e 2009/2010).

\begin{tabular}{|c|c|c|c|c|c|c|}
\hline \multirow{3}{*}{ Fontes de variação } & \multicolumn{6}{|c|}{ Caracteres determinantes da qualidade de sementes } \\
\hline & \multirow{2}{*}{ MMS (g) } & \multirow{2}{*}{ DM (\%) } & \multirow{2}{*}{ EA $(\%)$} & \multirow{2}{*}{$\operatorname{GER}(\%)$} & \multicolumn{2}{|c|}{ Tetrazólio } \\
\hline & & & & & VIG (\%) & VIB $(\%)$ \\
\hline \multicolumn{7}{|l|}{ Épocas de semeadura } \\
\hline E1 $(15 / 10)$ & $154,3 \mathrm{ab}$ & $3,8 \mathrm{c}$ & $77,8 \mathrm{~b}$ & $83,5 \mathrm{bc}$ & $59,8 \mathrm{~b}$ & $88,4 \mathrm{ab}$ \\
\hline E2 $(15 / 11)$ & $143,5 \mathrm{c}$ & $5,9 \mathrm{~b}$ & $78,9 \mathrm{~b}$ & $82,3 \mathrm{c}$ & $58,0 \mathrm{~b}$ & $81,7 \mathrm{c}$ \\
\hline E3 $(15 / 12)$ & $148,6 \mathrm{~b}$ & $9,4 \mathrm{a}$ & 85,4 a & 89,3 a & $68,2 \mathrm{a}$ & 90,6 a \\
\hline E4 $(15 / 01)$ & $155,8 \mathrm{a}$ & $2,9 \mathrm{c}$ & $80,4 \mathrm{~b}$ & $87,3 \mathrm{ab}$ & $59,6 \mathrm{~b}$ & $85,7 \mathrm{~b}$ \\
\hline Teste $\mathrm{F}$ & $* *$ & $* *$ & $* *$ & $* *$ & $* *$ & $* *$ \\
\hline \multicolumn{7}{|l|}{ Cultivares de soja } \\
\hline Don Mario 5.8i RR & $161,1 \mathrm{a}$ & $6,9 \mathrm{~b}$ & $70,6 \mathrm{~d}$ & $73,6 \mathrm{~d}$ & $63,0 \mathrm{ab}$ & $81,7 \mathrm{c}$ \\
\hline BMX Energia RR & $166,6 \mathrm{a}$ & $6,5 \mathrm{~b}$ & $82,2 \mathrm{~b}$ & $91,0 \mathrm{a}$ & $70,3 \mathrm{a}$ & $89,1 \mathrm{ab}$ \\
\hline BMX Força RR & $144,7 \mathrm{~b}$ & $2,4 \mathrm{c}$ & $78,1 \mathrm{bc}$ & $84,7 \mathrm{bc}$ & $68,0 \mathrm{a}$ & $85,1 \mathrm{bc}$ \\
\hline BRS 255 RR & $137,8 \mathrm{c}$ & $2,9 \mathrm{c}$ & $90,9 \mathrm{a}$ & $89,6 \mathrm{ab}$ & $62,9 \mathrm{~b}$ & $87,2 \mathrm{ab}$ \\
\hline BRS 294 RR & $142,7 \mathrm{~b}$ & $3,5 \mathrm{c}$ & $89,2 \mathrm{a}$ & $92,2 \mathrm{a}$ & $53,0 \mathrm{c}$ & $86,5 \mathrm{ab}$ \\
\hline BRS 295 RR & $150,4 \mathrm{a}$ & $10,9 \mathrm{a}$ & $72,9 \mathrm{~cd}$ & $82,5 \mathrm{c}$ & $51,3 \mathrm{c}$ & $90,1 \mathrm{a}$ \\
\hline Teste F & $* *$ & $* *$ & $* *$ & $* *$ & $* *$ & $* *$ \\
\hline Média geral & 150,6 & 5,5 & 80,6 & 85,6 & 61,4 & 86,6 \\
\hline $\mathrm{CV}(\%)$ & 5,4 & 8,6 & 4,6 & 4,9 & 5,4 & 3,1 \\
\hline
\end{tabular}

Tabela 2. Performance média das épocas de semeadura e de cultivares de soja, para seis caracteres determinantes da qualidade fisiológica de sementes oriundos do teste de tetrazólio (São Domingos, SC, safras 2008/2009 e 2009/2010).

\begin{tabular}{|c|c|c|c|c|c|c|}
\hline \multirow{3}{*}{ Fontes de variação } & \multicolumn{6}{|c|}{ Caracteres determinantes da qualidade de sementes } \\
\hline & \multicolumn{2}{|c|}{ Dano mecânico (\%) } & \multicolumn{2}{|c|}{ Umidade $(\%)$} & \multicolumn{2}{|c|}{ Percevejo (\%) } \\
\hline & $1-8$ & $6-8$ & $1-8$ & $6-8$ & $1-8$ & $6-8$ \\
\hline \multicolumn{7}{|l|}{ Épocas de semeadura } \\
\hline E1 $(15 / 10)$ & $2,44 \mathrm{~b}$ & $0,11 \mathrm{~b}$ & $73,25 \mathrm{a}$ & $5,94 \mathrm{~b}$ & $7,63 \mathrm{c}$ & $0,44 \mathrm{~b}$ \\
\hline E2 $(15 / 11)$ & $5,16 \mathrm{a}$ & $0,36 \mathrm{a}$ & $67,05 \mathrm{~b}$ & $9,25 \mathrm{a}$ & $16,41 \mathrm{a}$ & $0,75 \mathrm{~b}$ \\
\hline E3 $(15 / 12)$ & $2,72 \mathrm{~b}$ & $0,27 \mathrm{ab}$ & $66,38 \mathrm{~b}$ & $3,22 \mathrm{c}$ & $13,36 \mathrm{~b}$ & $0,94 \mathrm{~b}$ \\
\hline E4 $(15 / 01)$ & $1,91 \mathrm{~b}$ & $0,08 \mathrm{~b}$ & $55,66 \mathrm{c}$ & $7,02 \mathrm{~b}$ & $13,50 \mathrm{~b}$ & $2,44 \mathrm{a}$ \\
\hline Teste F & $* *$ & $* *$ & $* *$ & $* *$ & $* *$ & $* *$ \\
\hline \multicolumn{7}{|l|}{ Cultivares de soja } \\
\hline Don Mario 5.8i RR & $6,54 \mathrm{a}$ & $0,58 \mathrm{a}$ & $63,95 \mathrm{~b}$ & $4,87 \mathrm{~b}$ & $12,25 \mathrm{c}$ & $0,91 \mathrm{bc}$ \\
\hline BMX Energia RR & $5,87 \mathrm{a}$ & $0,37 \mathrm{ab}$ & $64,41 \mathrm{c}$ & $3,95 \mathrm{c}$ & $2,37 \mathrm{e}$ & $0,66 \mathrm{bcd}$ \\
\hline BMX Força RR & $2,33 \mathrm{~b}$ & $0,08 \mathrm{~b}$ & $74,37 \mathrm{a}$ & $11,12 \mathrm{a}$ & $5,29 \mathrm{~d}$ & $0,20 \mathrm{~d}$ \\
\hline BRS 255 RR & $2,08 \mathrm{~b}$ & $0,12 \mathrm{~b}$ & $65,00 \mathrm{~b}$ & $8,66 \mathrm{a}$ & $8,25 \mathrm{c}$ & $0,50 \mathrm{~cd}$ \\
\hline BRS 294 RR & $0,66 \mathrm{c}$ & $0,00 \mathrm{~b}$ & $64,29 \mathrm{~b}$ & $4,25 \mathrm{c}$ & $21,37 \mathrm{~b}$ & $3,04 \mathrm{a}$ \\
\hline BRS 295 RR & $0,87 \mathrm{c}$ & $0,08 \mathrm{~b}$ & $61,50 \mathrm{~b}$ & $5,29 \mathrm{~b}$ & $26,83 \mathrm{a}$ & $1,54 \mathrm{ab}$ \\
\hline Teste F & $* *$ & $* *$ & $* *$ & $* *$ & $* *$ & $* *$ \\
\hline Média geral & 3,06 & 0,20 & 65,59 & 6,36 & 12,72 & 1,14 \\
\hline CV $(\%)$ & 21,62 & 19,48 & 4,79 & 20,85 & 15,08 & 30,98 \\
\hline
\end{tabular}

Médias seguidas pela mesma letra, na coluna, indicam ausência de diferenças significativas ( $\mathrm{p} \leq 0,05)$, pelo teste Tukey. $* *$ significativo ( $\mathrm{p} \leq 0,01)$ pelo teste $\mathrm{F}$, extraído da análise de variância.

em Palotina, região oeste (Motta et al. 2002), e 30/10, em Maringá, região norte (Albrecht et al. 2008), como as mais adequadas para maximizar a qualidade fisiológica de sementes de soja. Essa variabilidade de resultados confirma a necessidade de estudos com épocas de semeadura em soja, em regiões geográficas específicas.

A cultivar Don Mario 5.8i RR apresentou germinação inferior a $80 \%$ (Tabela 1), porcentagem que determina o descarte de lotes, segundo os padrões para produção e comercialização de sementes de soja (Brasil 2005). A cultivar BRS 295 RR evidenciou elevado nível de dano mecânico, baixo vigor (Tabela 1) e alta ocorrência de danos por percevejo (Tabela 2).

Foi observado dano mecânico pelo teste de hipoclorito variando em 2,4-10,9\%, para o efeito de cultivares (Tabela 1). Entretanto, esse tipo de dano não foi captado no teste de tetrazólio (Tabela 2). Possivel- 
mente, isso ocorreu em virtude de danos ao tegumento oriundos da exposição alternada a condições ambientais úmidas e secas, durante o período de pós-maturidade fisiológica, fato comprovado pelos elevados índices de danos por umidade. As sucessivas contrações e expansões do volume das sementes pode conduzir à ruptura do tegumento (Pinto et al. 2007). Nessa situação, os danos foram contabilizados no teste de hipoclorito, mas isso não ocorreu no teste de tetrazólio.

Com exceção da BRS 295 RR, o restante das cultivares apresentou germinação superior a $80 \%$ e bons níveis de qualidade. A existência de variabilidade na expressão do potencial fisiológico de sementes, em cultivares de soja sujeitas a variação na época de semeadura, é descrita em outros estudos (Pereira et al. 2000, Ávila et al. 2003, Albrecht et al. 2008). Para o efeito de épocas de semeadura, o dano mecânico (hipoclorito de sódio), resultante do processo de trilha, foi inferior a $10 \%$, considerando-se o percentual limite (Krzyzanowski et al. 2004). Aliada ao tempo de armazenamento relativamente curto entre a colheita e as análises, essa condição não afetou os índices de germinação.

A deterioração por umidade e dano mecânico são, nessa ordem, os principais fatores que contribuem para a redução da qualidade de sementes de soja (Costa et al. 2005). De modo geral, a semeadura em 15/11 (E2) apresentou índices elevados desses caracteres, resultando em prejuízos à qualidade das sementes. Em E2 e E3 (15/12), os danos por umidade também foram elevados. Por outro lado, no somatório dos danos, a semeadura em dezembro apresentou menor ocorrência de sementes com danos na classe 6-8, consideradas não viáveis, contribuindo para a produção de sementes de qualidade superior.

A variação na ocorrência de deterioração por umidade ocorre, principalmente, devido a variações nos índices pluviométricos característicos de cada mês. Baixos índices de deterioração por umidade, danos por percevejos e danos mecânicos são determinantes na produção de sementes de melhor qualidade, no sul do Paraná e no Rio Grande do Sul (Costa et al. 2003).

O teste de tetrazólio merece destaque, devido à sua rapidez, precisão e, também, ao número de informações geradas (França Neto et al. 1998), possibilitando identificar os principais problemas que comumente afetam a qualidade de sementes. As cultivares de ciclo precoce (Don Mario 5.8i RR e BMX Energia RR) apresentaram maior ocorrência de dano mecânico, mensurado pelo teste de tetrazólio (Tabela 2). Para esse dano, as sementes provenientes da época E2 (15/11) foram as mais afetadas, sendo que as demais épocas não diferiram significativamente $(\mathrm{p} \leq 0,05)$.

Cultivares de soja precoce produzidas no Paraná têm a qualidade reduzida principalmente em razão de deterioração por umidade e danos mecânicos (Costa et al. 1994). Esses autores salientam que, para o grupo de cultivares de soja precoce, os danos causados por percevejos são menos prejudiciais à qualidade das sementes do que os danos mecânicos e a deterioração por umidade, fato também verificado no presente trabalho.

As lesões causadas por percevejos, principalmente devido à colonização dos tecidos das sementes por Nematospora coryli Peglion, trazem sérios prejuízos à qualidade das sementes (Costa et al. 2005). A semeadura antecipada em outubro (15/10) resultou em menores danos, em relação ao ataque de percevejos (Tabela 2). A maior ocorrência de dano causado por percevejo (TZ 6-8) ocorreu em E4 $(15 / 01)$, porém, deve-se enfatizar que o índice obtido ficou abaixo de 3\%. Índices de lesões de percevejos de 7-10 \% (TZ 6-8) são considerados restritivos ao desempenho da semente (França Neto et al. 1998).

A maior ocorrência de insetos sugadores em soja semeada em épocas tardias deve-se, em grande parte, ao processo de migração dos insetos para áreas onde a cultura ainda não completou o ciclo. Além disso, semeaduras tardias são acometidas com maior intensidade pela ferrugem asiática (Phakopsora pachyrhizi Sydow), a qual, associada a condições climáticas desfavoráveis, compromete o vigor das sementes (Pinto et al. 2011).

A variância total foi decomposta nas variâncias devido aos componentes genótipo (G) e ambiente (A), importantes fatores contribuintes do fenótipo da planta (Kandil et al. 2012), e à interação genótipo x ambiente (IGA), para cada caractere avaliado (Tabela 3).

Para os caracteres envelhecimento acelerado $(69,86 \%)$, germinação $(62,00 \%)$, massa de mil sementes $(57,23 \%)$, vigor $(53,05 \%)$, dano causado por percevejo (TZ 1-8) $(55,66 \%)$ e dano mecânico (TZ 1-8) (53,63\%), o componente genético apresentou elevada contribuição para a variação fenotípica. Para esses caracteres, a escolha correta da cultivar é essencial.

$\mathrm{O}$ efeito de ambiente foi menos expressivo para os caracteres germinação $(6,50 \%)$ e envelheci- 
Tabela 3. Proporções da variância total explicadas pelo efeito de genótipo (G), ambiente (A) e da interação entre eles (IGA), considerando-se a média dos dois anos, de um total de doze caracteres determinantes da qualidade fisiológica de sementes de soja (São Domingos, SC, safras 2008/2009 e 2009/2010).

\begin{tabular}{lrrr}
\hline \multirow{2}{*}{\multicolumn{1}{c}{ Caracteres }} & \multicolumn{3}{c}{ Fontes de variação $^{(\mathrm{a})}$} \\
\cline { 2 - 4 } & $\mathrm{G}$ & \multicolumn{1}{c}{$\mathrm{A}$} & \multicolumn{1}{c}{ IGA } \\
\hline Massa de mil sementes & 57,23 & 22,37 & $20,39^{* *}$ \\
Dano mecânico & 37,56 & 36,83 & $25,60^{* *}$ \\
Envelhecimento acelerado & 69,86 & 9,54 & $20,60^{* *}$ \\
Germinação & 62,00 & 6,50 & $22,05^{* *}$ \\
Vigor & 53,05 & 18,43 & $28,52^{* *}$ \\
Viabilidade & 39,97 & 24,79 & $35,24^{* *}$ \\
\hline Tetrazólio & & & \\
Dano mecânico (TZ 1-8) & 53,63 & 13,71 & $32,66^{* *}$ \\
Dano mecânico (TZ 6-8) & 34,34 & 20,90 & $44,76^{* *}$ \\
Umidade (TZ 1-8) & 19,62 & 47,76 & $32,62^{* *}$ \\
Umidade (TZ 6-8) & 29,27 & 23,15 & $47,28^{* *}$ \\
Percevejo (TZ 1-8) & 55,66 & 18,38 & $25,96^{* *}$ \\
Percevejo (TZ 6-8) & 40,40 & 20,43 & $39,18^{* *}$ \\
\hline Média & 46,05 & 21,90 & 31,24 \\
\hline
\end{tabular}

(a) Estimativas obtidas pela análise AMMI, por meio do programa GGE biplot. ** significância $(\mathrm{p} \leq 0,01)$ obtida na análise de variância para o efeito da interação (IGA), em cada caractere. mento acelerado (9,54\%), porém, pronunciado nos caracteres dano por umidade (TZ 1-8) (47,76 \%) e dano mecânico $(36,83 \%)$. De maneira geral, para todos os caracteres avaliados, o efeito de genótipo aparece como determinante na explicação da variação fenotípica total (46,50\%, em média), comprovando a divergência entre cultivares, na expressão da qualidade de sementes.

Na sequência, o efeito da interação respondeu por $31,24 \%$ da variação, permitindo inferir que existe necessidade da adequação de épocas de semeadura específicas para cada cultivar. Por fim, o efeito de ambiente respondeu por $21,90 \%$ da variação, demonstrando a importância da escolha da época de semeadura na produção de sementes de alta qualidade. A presença do efeito ambiental e não apenas genético na variação fenotípica dos caracteres informativos da qualidade fisiológica de sementes de soja também é relatado em outros estudos (Pereira et al. 2000, Vasconcelos et al. 2009, Gomes et al. 2012).

Na Figura 2, consta a associação dos caracteres avaliados e cultivares de soja, com as épocas de
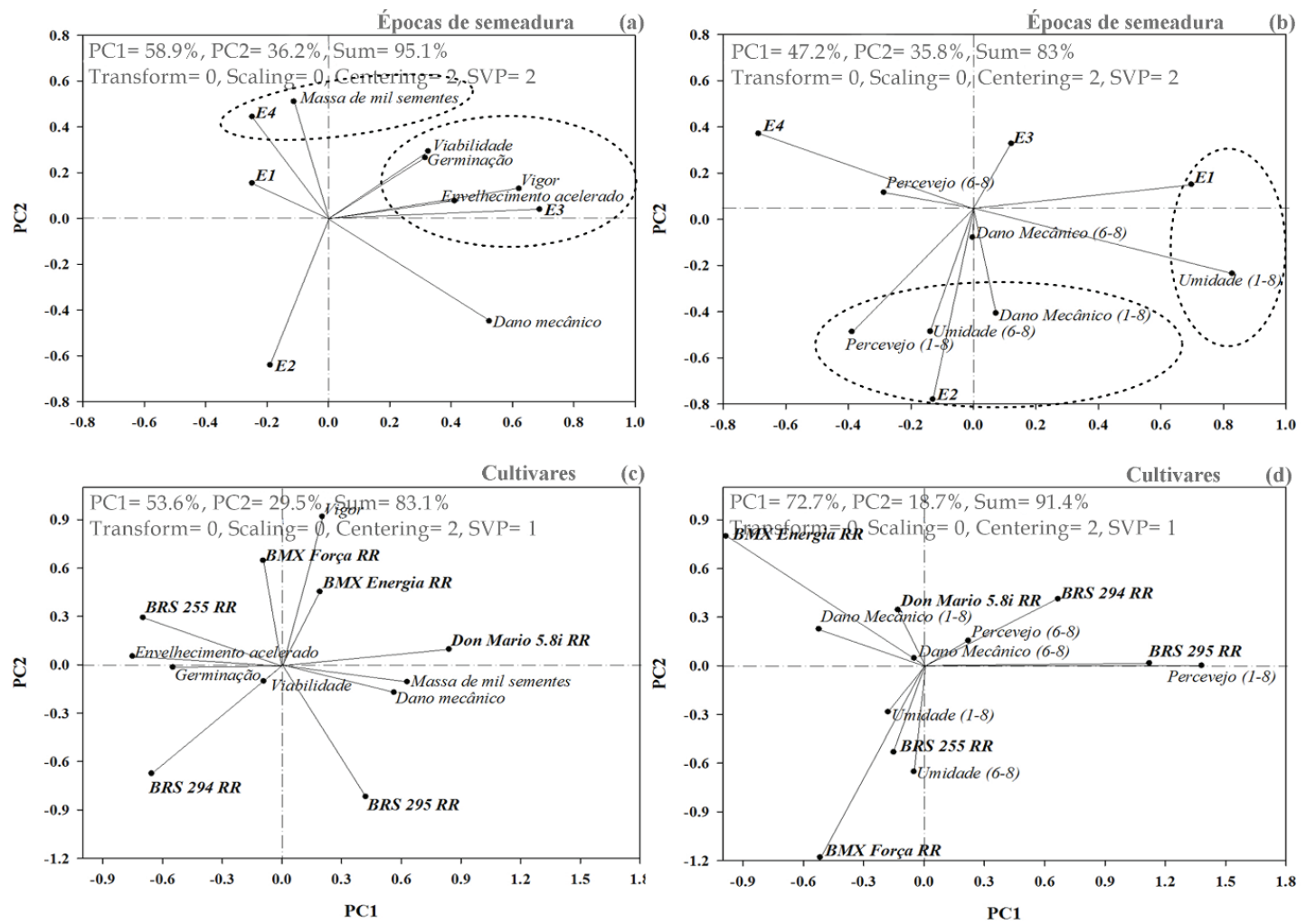

Figura 2. Análises GGE biplot: (a) e (b) = estimativa da relação existente entre quatro épocas de semeadura de soja e parâmetros determinantes da qualidade fisiológica de sementes; (c) e (d) = estimativa da relação existente entre seis cultivares de soja e parâmetros determinantes da qualidade fisiológica de sementes. Épocas de semeadura: E1 = 15/10, E2 = 15/11, E3 = 15/12 e E4 = 15/01, de cada safra agrícola (São Domingos, SC, safras 2008/2009 e 2009/2010). 
semeadura testadas. Na análise gráfica GGE biplot, quanto menor for o ângulo entre dois vetores, maior é a correlação entre esses vetores (Yan \& Kang 2003). Ângulos superiores indicam associação negativa, enquanto ângulos iguais a $90^{\circ}$ indicam ausência de correlação (Yan \& Kang 2003).

Observa-se que a terceira época de semeadura $(15 / 12)$ foi positivamente associada à viabilidade, germinação, vigor e envelhecimento acelerado (Figura 2a), e não foi associada aos caracteres indicadores de danos na semente avaliados pelo teste de tetrazólio (Figura 2b). Essa estratégia de análise gráfica com bases multivariadas permite uma melhor interpretação dos dados.

A época de semeadura E2 (15/11) mostrou-se associada à maior ocorrência de danos causados por umidade (TZ 6-8), dano mecânico (TZ 1-8) e percevejo (TZ 1-8). Danos resultantes do ataque de percevejos também estiveram associados a E4 (15/01) (Figura 2b). Nesse sentido, E3 (15/12) foi superior em potencializar a qualidade de sementes, pois não apresentou associação com nenhum desses caracteres.

Os últimos estádios vegetativos das cultivares semeadas em E3 coincidiram com um período de baixa precipitação (Figura 1), o que, provavelmente, contribuiu para a redução dos danos. A massa de mil sementes foi altamente associada à quarta época de semeadura (15/01) (Figura 2a), embora haja relatos de que esse caractere não oscile, quando da variação de épocas de semeadura (Braccini et al. 2004).

As cultivares BMX Força RR e BRS 255 RR associaram-se positivamente aos caracteres vigor, envelhecimento acelerado e germinação, e negativamente com dano mecânico (Figura $2 \mathrm{c}$ ), porém, estiveram associadas a um maior dano por umidade (Figura 2d). BMX Energia RR mostrou-se altamente associada ao vigor. As cultivares Don Mario 5.8i RR e BRS 295 RR associaram-se à massa de mil sementes, porém, também apresentaram maior dano mecânico. Danos à qualidade fisiológica oriundos do ataque de percevejos estiveram positivamente associados às cultivares BRS 295 RR e BRS 294 RR, indicando que, além da época de semeadura, a escolha correta da cultivar é determinante na produção de sementes de qualidade.

A variabilidade genética para parâmetros determinantes da qualidade de sementes é também reportada em outros estudos (Pereira et al. 2000, Motta et al. 2002, Santos et al. 2007), sendo associada à composição química da semente, espessura do tegumento, características da vagem e reação da planta a pragas e doenças.

No ambiente de estudo, historicamente, os acumulados pluviométricos são mais elevados nos meses de janeiro e fevereiro ( $\left.>190 \mathrm{~mm}^{\text {mês }}{ }^{-1}\right)$ e menores nos meses de março, abril e maio ( $>175 \mathrm{~mm}^{\text {mês }}{ }^{-1}$ ) (Simepar 2010). Portanto, semeaduras em outubro e novembro estão mais propensas à deterioração por umidade das sementes na pré-colheita, fato observado no presente estudo. Além disso, temperaturas máximas elevadas são comumente registradas nos primeiros meses do ano (janeiro, fevereiro e março: $>29^{\circ} \mathrm{C}$ ) (Simepar 2010), o que contribui para a redução no potencial fisiológico. Além da escolha correta da época de semeadura, é primordial o efetivo controle de percevejo, em épocas de semeadura tardias.

\section{CONCLUSÕES}

1. Para a região oeste de Santa Catarina, semeaduras em meados de dezembro são recomendadas para a produção de sementes de soja com qualidade superior.

2. Para a produção de sementes de alta qualidade, o efeito de genótipo aparece como determinante, contudo, os efeitos de ambiente e da interação entre genótipo e ambiente são pronunciados, justificando a identificação de épocas de semeadura específicas para cada cultivar.

\section{REFERÊNCIAS}

ALBRECHT, L. P. et al. Qualidade fisiológica e sanitária das sementes sob semeadura antecipada da soja. Scientia Agraria, Curitiba, v. 9, n. 4, p. 445-454, 2008.

AMORIM, F. A. et al. Época de semeadura no potencial produtivo de soja em Uberlândia - MG. Semina: Ciências Agrárias, Londrina, v. 32, n. 1, p. 1793-1802, 2011.

ÁVILA, M. R. et al. Sowing seasons and quality of soybean seeds. Scientia Agricola, Piracicaba, v. 60, n. 2, p. 245-252, 2003.

BRACCINI, A. de L. et al. Características agronômicas e rendimento de sementes de soja na semeadura realizada no período de safrinha. Bragantia, Campinas, v. 63, n. 1, p. 81-92, 2004.

BRASIL. Ministério de Agricultura, Pecuária e Abastecimento. Instrução normativa n. 25, de 16 de dezembro de 2005. Diário Oficial da República Federativa do Brasil, Poder Executivo, Brasília, DF, 16 dez. 2005. p. 18. 
BRASIL. Ministério da Agricultura, Pecuária e Abastecimento. Regras para análise de sementes. Brasília, DF: MAPA, 2009.

COSTA, J. A.; MARCHEZAN, E. Características dos estádios de desenvolvimento da soja. Campinas: Fundação Cargill, 1982.

COSTA, N. P. da et al. Qualidade fisiológica, física e sanitária de sementes de soja produzidas no Brasil. Revista Brasileira de Sementes, Londrina, v. 25, n. 1, p. 128-132, 2003.

COSTA, N. P. et al. Validação do zoneamento ecológico do Estado do Paraná para produção de sementes de soja. Revista Brasileira de Sementes, Londrina, v. 27, n. 1, p. 37-44, 2005.

COSTA, N. P. da et al. Zoneamento ecológico do Estado do Paraná para a produção de sementes de cultivares precoces de soja. Revista Brasileira de Sementes, Londrina, v. 16, n. 1, p. 12-19, 1994.

CRUZ, C. D. GENES: a software package for analysis in experimental statistics and quantitative genetics. Acta Scientiarum, Londrina, v. 35, n. 3, p. 271-276, 2013.

FOOD AND AGRICULTURE ORGANIZATION OF THE UNITED NATIONS (FAO). Statistical databases: agriculture. 2014. Disponível em: <http://faostat3.fao. org/faostat-gateway/go/to/download/Q/QC/E > . Acesso em: 18 fev. 2014.

FRANÇA NETO, J. B.; KRZYZANOWSKI, F. C.; COSTA, N. P. da. O teste de tetrazólio em sementes de soja. Londrina: Embrapa-CNPSo, 1998.

GABRIEL, K. R. The biplot graphic display of matrices with application to principal component analysis. Biometrika, Oxford, v. 58, n. 3, p. 453-467, 1971.

GOMES, G. D. R. et al. Produção e qualidade fisiológica de sementes de soja em diferentes ambientes de cultivo. Semina: Ciências Agrárias, Londrina, v. 33, n. 1, p. 25932604, 2012.

JAUREGUYA, L. M. et al. Planting date and delayed harvest effects on soybean seed composition. Crop Science, Madison, v. 53, n. 5, p. 2162-2175, 2013.

KANDIL, A. A. et al. Performance of some promising genotypes of soybean under different planting dates using biplots analysis. Journal of Basic \& Applied Sciences, Karachi, v. 8, n. 2, p. 379-385, 2012.

KRZYZANOWSKI, F. C.; FRANÇA-NETO, J. de B.; COSTA, N. P. da. Teste do hipoclorito de sódio para semente de soja. Londrina: Embrapa Soja, 2004. (Circular técnica, 37).

MARCOS FILHO, J. Fisiologia de sementes de plantas cultivadas. Piracicaba: Fealq, 2005.
MARCOS FILHO, J. Teste de envelhecimento acelerado. In: KRZYZANOWSKI, F. C. et al. (Eds.). Vigor de sementes: conceitos e testes. Londrina: Abrates, 1999. p. 1-24.

MEOTTI, G. V. et al. Épocas de semeadura e desempenho agronômico de cultivares de soja. Pesquisa Agropecuária Brasileira, Brasília, DF, v. 47, n. 1, p. 14-21, 2012.

MEROTTO JUNIOR, A.; VIDAL, R. A. (Orgs.). Indicações técnicas para a cultura da soja no Rio Grande do Sul e em Santa Catarina 2009/2010. Porto Alegre: UFRGS, 2009.

MOTTA, I. de S. et al. Época de semeadura em cinco cultivares de soja: II. Efeito na qualidade fisiológica das sementes. Acta Scientiarum Agronomy, Maringá, v. 24, n. 5, p. 1281-1286, 2002.

OMETTO, J. C. Bioclimatologia vegetal. São Paulo: Agronômica Ceres, 1981.

PARANÁ. Secretaria da Agricultura e Abastecimento. Departamento de Economia Rural. Produção agropecuária: soja. 2014. Disponível em: <http://www.agricultura.pr.gov. $\mathrm{br} /$ modules $/$ conteudo/conteudo.php? conteudo $=137 \mathrm{P}$. Acesso em: 17 fev. 2014.

PEDERSEN, P.; LAUER, J. G. Soybean growth and development in various management systems and planting dates. Crop Science, Madison, v. 44, n. 2, p. 508-515, 2004.

PEREIRA, E. B. C.; PEREIRA, A. V.; FRAGA, A. C. Qualidade de sementes de cultivares precoces de soja produzidas em três épocas. Pesquisa Agropecuária Brasileira, Brasília, DF, v. 35, n. 8, p. 1653-1662, 2000.

PINTO, T. L. F.; CÍCERO, S. M.; FORTI, V. A. Avaliação de danos por umidade, em sementes de soja, utilizando a técnica da análise de imagens. Revista Brasileira de Sementes, Londrina, v. 29, n. 3, p. 31-38, 2007.

PINTO, T. L. F. et al. Fungicidas foliares e a doença ferrugem asiática na produção e na qualidade de sementes de soja. Revista Brasileira de Sementes, Brasília, DF, v. 33, n. 4, p. 680-688, 2011.

RAHMAN, M. M.; RAHMAN, M. M.; HOSSAIN, M. $M$. Effect of sowing date on germination and vigour of soybean (Glycine max (L.) Merr) seeds. The Agriculturists, Bangladesh, v. 11, n. 1, p. 67-75, 2013.

SANTOS, E. L. et al. Qualidade fisiológica e composição química das sementes de soja com variação na cor do tegumento. Revista Brasileira de Sementes, Londrina, v. 29, n. 1, p. 20-26, 2007.

SCHÖFFEL, E. R.; VOLPE, C. A. Eficiência de conversão da radiação fotossinteticamente ativa interceptada pela soja para a produção de fitomassa. Revista Brasileira de Agrometeorologia, Santa Maria, v. 9, n. 2, p. 241-249, 2001. 
SISTEMA METEOROLÓGICO DO PARANÁ (Simepar). Dados meteorológicos de Pato Branco. Curitiba: Simepar, 2010.

STÜLP, M. et al. Desempenho agronômico de três cultivares de soja em diferentes épocas de semeadura em duas safras. Ciência e Agrotecnologia, Lavras, v. 33, n. 5, p. 1240-1248, 2009.

THOMÉ, V. M. et al. Zoneamento agrícola para a cultura da soja em Santa Catarina. In: CONGRESSO BRASILEIRO DE AGROMETEOROLOGIA, 10., 1997, Piracicaba. Anais... Piracicaba: Sbagro, 1997. p. 33.

TOLEDO, M. Z.; CAVARIANI, C.; FRANÇA-NETO, J. de B. Qualidade fisiológica de sementes de soja colhidas em duas épocas após dessecação com glyphosate. Revista Brasileira de Sementes, Londrina, v. 34, n. 1, p. 134-142, 2012.

UNITED STATES DEPARTMENT OF AGRICULTURE (USDA). World agricultural supply and demand estimates: February 10, 2014. 2014. Disponível em: <http://www. usda.gov/oce/commodity/wasde/>. Acesso em: $17 \mathrm{fev}$. 2014.

VASCONCELOS, E. S. de et al. Qualidade fisiológica de sementes de cultivares e linhagens de soja no Estado de Minas Gerais. Acta Scientiarum Agronomy, Maringá, v. 31, n. 2, p. 307-312, 2009.

YAN, W. GGE biplot: a Windows application for graphical analysis of multi-environment trial data and other types of two-way data. Agronomy Journal, Madison, v. 93, n. 5, p. 1111-1118, 2001.

YAN, W. K. et al. Cultivar evaluation and megaenvironment investigation based on the GGE biplot. Crop Science, Madison, v. 40, n. 3, p. 597-605, 2000.

YAN, W.; KANG, M. S. GGE biplot analysis: a graphical tool for breeders, geneticists, and agronomists. Boca Raton: CRC Press, 2003.

ZOBEL, R. W.; WRIGHT, M. J.; GAUCH, H. G. Statistical analysis of a yield trial. Agronomy Journal, Madison, v. 80, n. 3, p. 388-393, 1988. 